\title{
Genome-wide characterization of simple sequence repeats in Pyrus bretschneideri and their application in an analysis of genetic diversity in pear
}

Huabai Xue ${ }^{1,2 \dagger}$, Pujuan Zhang ${ }^{1 \dagger}$, Ting Shi ${ }^{1}$, Jian Yang ${ }^{2}$, Long Wang ${ }^{2}$, Suke Wang ${ }^{2}$, Yanli Su' ${ }^{2}$, Huirong Zhang ${ }^{2}$, Yushan Qiao ${ }^{1 *}$ and Xiugen $\mathrm{Li}^{2^{*}}$

\begin{abstract}
Background: Pear (Pyrus spp.) is an economically important temperate fruit tree worldwide. In the past decade, significant progress has been made in pear molecular genetics based on DNA research, but the number of molecular markers is still quite limited, which hardly satisfies the increasing needs of geneticists and breeders.

Results: In this study, a total of 156,396 simple sequence repeat (SSR) loci were identified from a genome sequence of Pyrus bretschneideri 'Dangshansuli'. A total of 101,694 pairs of SSR primers were designed from the SSR loci, and 80,415 of the SSR loci were successfully located on 17 linkage groups (LGs). A total of 534 primer pairs were synthesized and preliminarily screened in four pear cultivars, and of these, 332 primer pairs were selected as clear, stable, and polymorphic SSR markers. Eighteen polymorphic SSR markers were randomly selected from the 332 polymorphic SSR markers in order to perform a further analysis of the genetic diversity among 44 pear cultivars. The 14 European pears and their hybrid materials were clustered into one group (European pear group); 29 Asian pear cultivars were clustered into one group (Asian pear group); and the Zangli pear cultivar 'Deqinli' from Yunnan Province, China, was grouped in an independent group, which suggested that the cultivar 'Deqinli' is a distinct and valuable germplasm resource. The population structure analysis partitioned the 44 cultivars into two populations, Pop 1 and Pop 2. Pop 2 was further divided into two subpopulations. Results from the population structure analysis were generally consistent with the results from the UPGMA cluster analysis.
\end{abstract}

Conclusions: The results of the present study showed that the use of next-generating sequencing to develop SSR markers is fast and effective, and the developed SSR markers can be utilized by researchers and breeders for future pear improvement.

Keywords: Pyrus bretschneideri, Simple sequence repeat, Genetic diversity, Pear

\section{Background}

Pear (Pyrus spp., $2 \mathrm{n}=2 \mathrm{x}=34$ ) is an economically important temperate fruit tree worldwide. The genus Pyrus belongs to the subtribe Malinae of the tribe Maleae in the subfamily Amygdaloideae of the family Rosaceae [1], with three known secondary centers of

\footnotetext{
* Correspondence: qiaoyushan@njau.edu.cn; lixiugen@sina.com ${ }^{+}$Huabai Xue and Pujuan Zhang contributed equally to this work.

${ }^{1}$ College of Horticulture, Nanjing Agricultural University, Nanjing 210095, China ${ }^{2} Z$ hengzhou Fruit Research Institute, Chinese Academy of Agricultural Sciences (CAAS), Key Laboratory of Fruit Breeding Technology of Ministry of Agriculture, Zhengzhou 450009, China
}

origin: the Chinese center, the Central Asian center, and the Near Eastern center [2].

Because pear is self-incompatible and has a long juvenile period, the traditional breeding method based only on general appearance and agronomic performance is time consuming and money intensive. With the development of molecular breeding technology, marker-assisted selection, an important tool now in the improvement of many crops, permits the rapid identification of key individuals that harbor useful genes and offers promise for pear breeding. Providing as many molecular markers

(c) The Author(s). 2018 Open Access This article is distributed under the terms of the Creative Commons Attribution 4.0 International License (http://creativecommons.org/licenses/by/4.0/), which permits unrestricted use, distribution, and reproduction in any medium, provided you give appropriate credit to the original author(s) and the source, provide a link to the Creative Commons license, and indicate if changes were made. The Creative Commons Public Domain Dedication waiver (http://creativecommons.org/publicdomain/zero/1.0/) applies to the data made available in this article, unless otherwise stated. 
as possible in the whole genome is the prerequisite for the construction of a genetic linkage map, gene mapping, molecular marker assisted selection (MAS) and other genomics studies [3-5].

Microsatellites, or simple sequence repeats (SSRs), are tandemly repeated units of 1-6 nucleotide sequence motifs flanked by unique sequences [6-8]. Given their wide distribution throughout the genome, codominant inheritance, and high polymorphism [7, 9, 10], SSRs have become desirable molecular markers for the construction of genetic linkage maps [11], genetic relationship identification [12], fingerprinting [13] and genetic diversity analyses [14-17].

Currently, several efforts have also been made to develop SSR markers in pears [17-26]. Yamamoto et al. [21-23] developed SSR markers, which showed a high degree of polymorphism, in Japanese pear (Pyrus pyrifolia Nakai) for the first time by using an enriched genomic library, RAHM (random amplified hybridization microsatellites) and 5' anchored PCR methods. FernándezFernández et al. developed 19 microsatellite primer pairs from the genomic DNA of European pear (Pyrus communis L.) [19]. Nishitani et al. developed 73 expressed sequence tag (EST)-simple sequence repeat (SSR) markers based on ESTs derived from 11 cDNA libraries of the Japanese pear cultivar 'Housui', and the SSR markers showed good transferability to other species in the Rosaceae [20]. Yamamoto et al. developed 237 SSR markers from a genome sequencing analysis in Japanese pear, and most of them successfully added to genetic linkage maps of pear [24]. Fan et al. reported a set of 120 SSRs that was developed from the newly assembled pear sequence and evaluated polymorphisms in seven genotypes of pear from different genetic backgrounds [18]. Chen et al. [11] developed 1341 SSR markers based on the genome sequence of the 'Dangshansuli' pear [27]. There are also many SSR loci from transcriptomes of different tissues of pear that have been identified and reported [17, 25, 26].

Although a great deal of effort has been made for the development of SSRs based on the genome sequence $[11,15,18]$ since the genome of Pyrus bretschneideri Rehd was completely sequenced [27], the number of SSRs publicly available for pear is still insufficient for some applications, such as the construction of high-resolution linkage maps, QTL mapping analyses, increasing marker density in specific map regions and so on. Therefore, more efforts are still needed to develop SSR markers for further progress in pear genetics and genomics studies. In the present study, we aimed to: (1) develop SSR markers from publicly available scaffold sequence of the pear genome; (2) anchor the SSR markers to the existing reference genetic map; and (3) evaluate SSR polymorphism and applications in the analysis of genetic diversity.

\section{Results}

Identification and distribution of SSRs in the genome

A total of 156,396 SSR motifs were identified within the scaffold sequences. Of the total SSRs identified, mono-nucleotide repeat motifs $(98,939,63.26 \%)$ were predominant, followed by di-nucleotide repeat motifs $(41,546,26.56 \%)$, tri-nucleotide repeat motifs $(11,798$, 7.54\%), tetra-nucleotide repeat motifs (3271, 2.09\%), penta-nucleotide repeat motifs $(593,0.38 \%)$ and hexa-nucleotide repeat motifs $(249,0.16 \%)$. For the mono-, diand tri-nucleotide repeat motifs, the frequency is as high as $97.36 \%$ in total. The most abundant mono-nucleotide motif was $\mathrm{A} / \mathrm{T}$, accounting for $95.94 \%$ of mono-nucleotide motif repeats. In di-nucleotide repeats, the most frequent motif was AG/CT (42.34\%), followed by AT/TA (40.36\%). Of the tri-nucleotide repeats, AAG/CTT and AAT/ATT were the most abundant, accounting for 27.61 and $26.45 \%$, respectively. The number of each major SSR type identified is summarized in Additional file 1: Figure S1; Additional file 2: Table S1 and Additional file 3: Table S2.

Further comparison of the number of SSRs with different repeat motifs revealed that the number of SSRs with shorter motifs was much higher than that with longer motifs. In all repeat types, the number of SSRs exceeded 10,000 only for the mono-nucleotide repeat motifs with the repeat numbers of 12,13 and 14 . The number of SSRs for the mono-, di-, tri-, and tetra-nucleotide repeat motif types were more than 1000 when the repeat numbers was within $28,17,7$ and 5 , respectively, while the number of SSRs was not more than 500 for the pentaand hexa-nucleotide repeat motifs even with the least number of repeats (Additional file 4: Table S3).

\section{Functional annotation of SSR loci}

By searching for genomic annotation documents (GFF), among the 156,396 SSR loci identified, there are 120,469 SSR loci that were located within or near the 28,819 genes. Among them, the number of SSRs in the intergenic region was 62,984 (40.27\%), which was the highest, followed by the number of SSRs located in the intron of the gene $(20,085,12.84 \%)$. There are $23,953(15.32 \%)$ SSRs in total located within the $1 \mathrm{~KB}$ area upstream of a transcription start site, within the $1 \mathrm{~KB}$ area downstream of a transcription start site, or within a $1 \mathrm{~KB}$ area upstream of a gene while downstream of another gene. There are 5052 SSRs in total in the region of 5' UTR, or in the region of 3' UTR. Only 2135 SSRs were located in the exon region of coding genes (Additional file 5: Table S4).

All the 28,819 genes associated with the 120,469 SSRs loci were searched using BLASTx against the National Central for Biotechnology Information (NCBI) database, and 24,333 genes were annotated within the database. These genes were also aligned by BLASTx to the protein database KEGG, and 4835 genes were annotated within 
the KEGG database. These genes were enriched into 128 pathways of 6 KEGG A classes and 21 KEGG B classes. With the 6 KEGG A classes, 417 genes were enriched into Cellular Processes, 385 genes were enriched into Environmental Information Processing, 1990 genes were enriched into Genetic Information Processing, 69 genes were enriched into Human Diseases, 4674 genes were enriched into Metabolism, and 217 genes were enriched into Organismal Systems (Fig. 1).

GO functional annotations of 28,819 genes were analyzed by the Blast2GO software (version 2.6.0+) and classified further using GO terms. After acquiring a GO annotation for every gene, we used WEGO to perform a GO functional classification for all the genes. Based on the GO annotation, 15,808 (54.85\%) genes of pear were assigned to 112,706 GO-term annotations. These annotations were summarized into $48 \mathrm{GO}$-terms of the three major categories. Of them, biological process $(53,051$, $47.07 \%)$ comprised the majority of the GO annotations, followed by cellular component $(39,492,35.04 \%)$ and molecular function $(20,163,17.89 \%)$. Genes were mostly enriched in the terms of metabolic process (10257), cellular process (10158), cell (9421), cell part (9405) and binding (9088) (Fig. 2).

\section{Development of SSR primers and determination of their linkage groups}

A total of 153,008 (97.83\%) primer pairs were designed from the 156,396 identified SSRs. After deletion of the SSR loci with more than one identical primer, a total of 101,694 SSR loci (Additional file 6: Table S5, 65.02\%) were eventually retained, including 63,317 (62.26\%) mono-nucleotide repeat motifs, 27,561 (27.10\%) di-nucleotide repeat motifs, $8261(8.12 \%)$ tri-nucleotide repeat motifs, 1962 (1.93\%) tetra-nucleotide repeat motifs, 409 (0.40\%) penta-nucleotide repeat motifs and $184(0.18 \%)$ hexa-nucleotide repeat motifs (Additional file 3: Table S2).

According to the data of the high-density genetic map of pear [28], we designated the SSR loci to the corresponding linkage group (LG) and provided the scaffolds' genetic position to the SSR loci derived from the scaffolds as an estimated reference position in the linkage group. Of the 101,694 SSR loci, a total of 61,160 SSR loci were localized to a single linkage group. The 19,255 SSR loci may be located in one of the 2-3 linkage groups, but the specific linkage group could not be identified. A total of 21,279 SSR loci could not be located on a specific linkage group, and the broad linkage group could not be determined. Of the 17 linkage groups, the SSR loci were the least in the seventh linkage group, 1011 in total; followed by first linkage group, with 1491 SSR loci; and the fifteenth linkage group had the largest number of SSR loci, 7030 in total (Additional file 6: Table S5; Additional file 7: Table S6).

\section{Polymorphism of SSR primers}

A total of 534 SSR primer pairs were tested for their ability to amplify DNA and detect polymorphism in 4 cultivars using a PAGE analysis (Fig. 3; Additional file 8: Table S7). Among them, 27 SSR primer pairs failed to amplify the product (5.06\%), and the rest of the 507 SSR primer pairs could amplify the expected product (94.94\%).

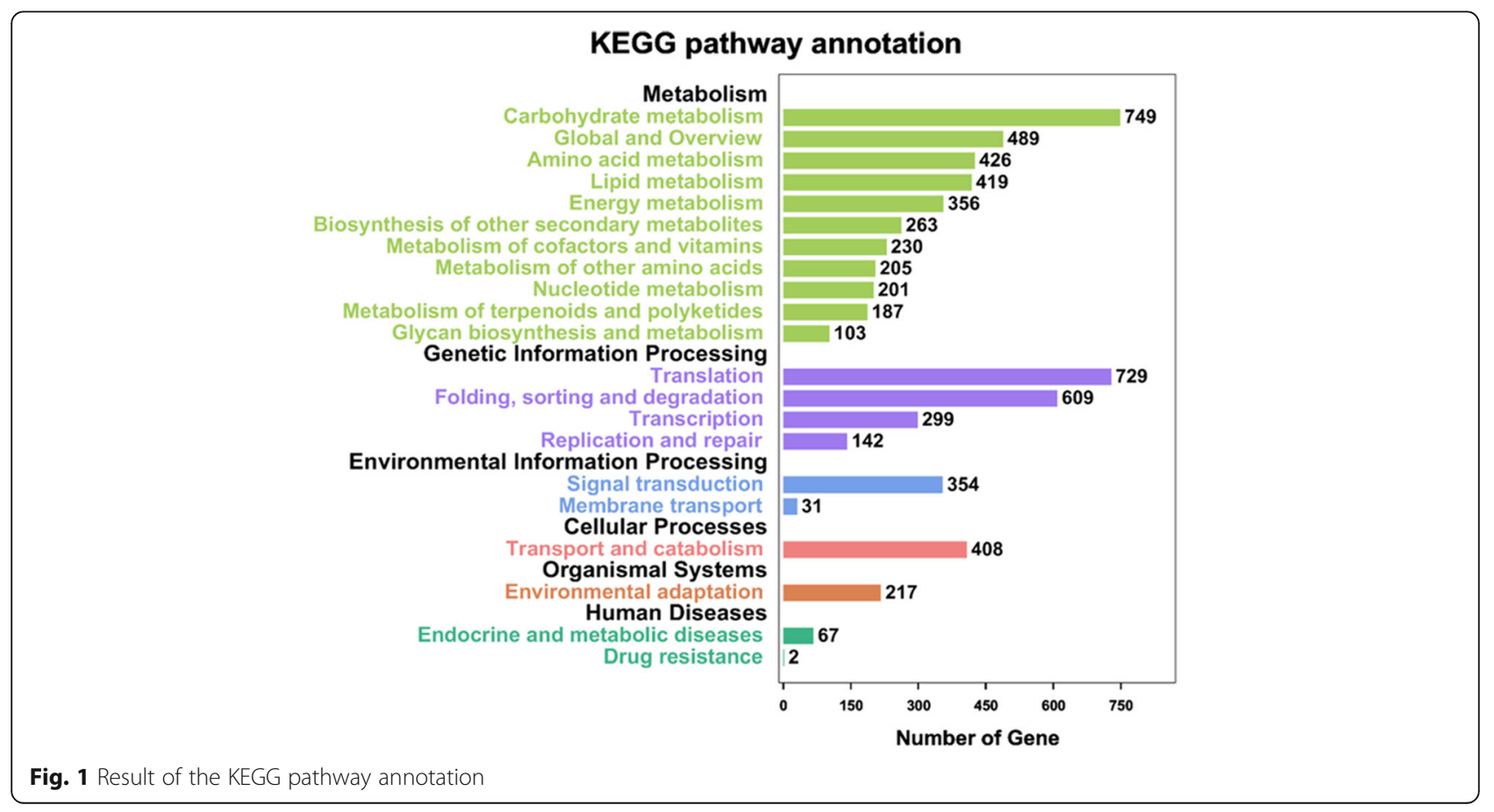




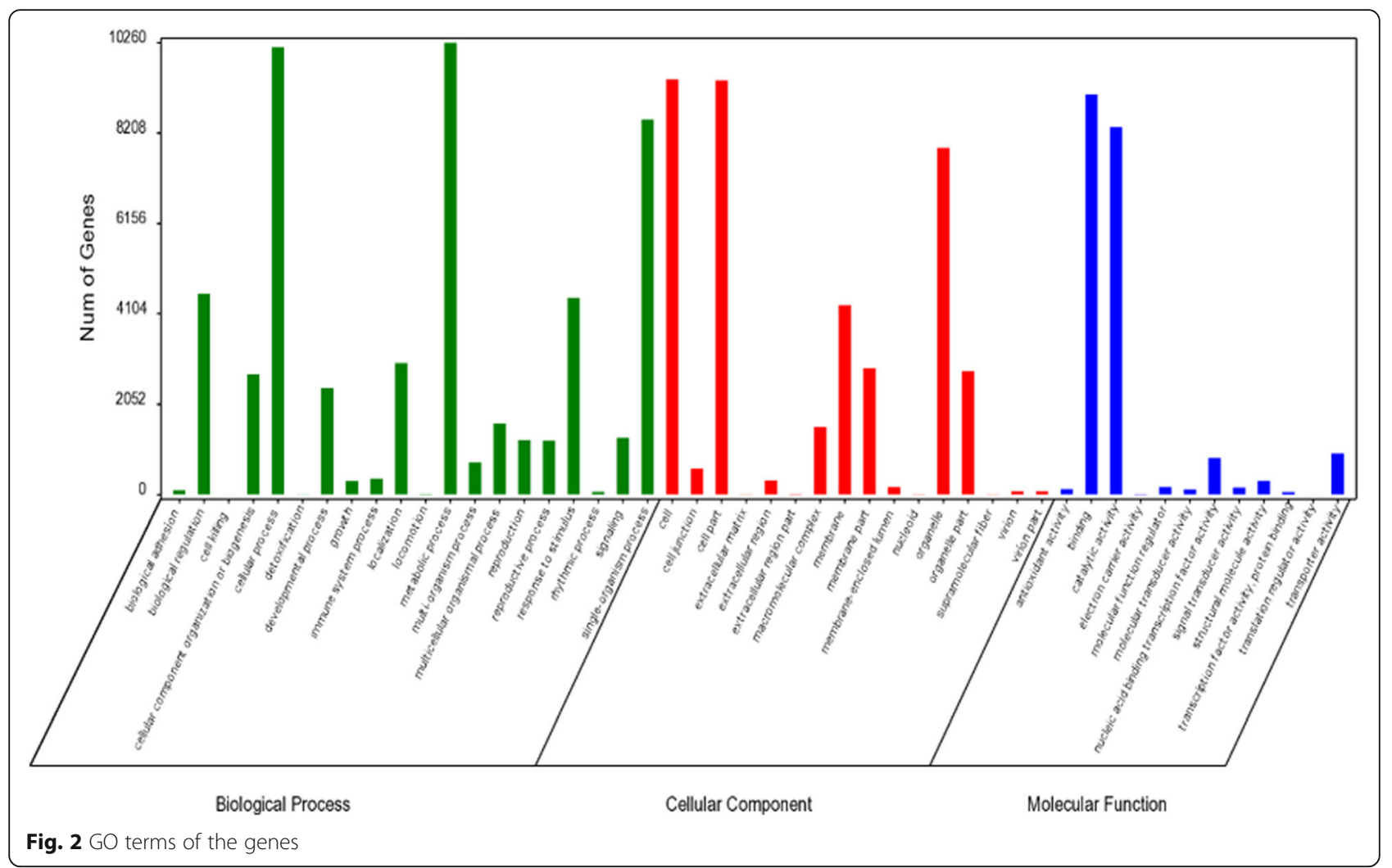

Through further screening optimization, we screened out $332(62.17 \%)$ SSR primer pairs that have clear banding patterns and are easy to identify (Additional file 9: Table S8). They can be used not only in the genetic population analysis but also in germplasm identification and a genetic diversity analysis.

\section{Assessment of the genetic relationship among 44 pear cultivars by SSR markers}

To verify the applicability of the newly developed SSR primer, a total of 44 pear varieties were genotyped by 18 SSR primers. The results showed that 18 pairs of primers amplified a product with a size range of 103275 bp (two markers as examples, see Additional file 10: Figure S2). Most of the actual size of the amplified fragments matched or was very close to the size of the expected fragments; only the amplified products of primer
Pb2L17N16884 were different from the expected fragment size. The 18 pairs of SSR primers detected 5-15 alleles in the tested cultivars, with an average allele number of 10.56. All the alleles were grouped into 11-26 genotypes, with an average genotype number of 19.22. The observed heterozygosity (No) among the SSR primers ranged from 0.2826 (Pb3LUN6782) to -0.8913 (Pb2L17N16884), with an average No of 0.6763. The polymorphism information content (PIC) ranged from $0.6064-0.8814$, with an average PIC of 0.7808 (Additional file 11: Table S9).

In the UPGMA cluster analysis, the 44 pear accessions were classified into three groups (For similarity coefficient among 44 pear cultivars, see Additional file 12: Table S10). The 'Deqinli' of the Zangli pear is grouped into one group individually, which is in a special position in the dendrogram. Among the other 43 varieties, 14

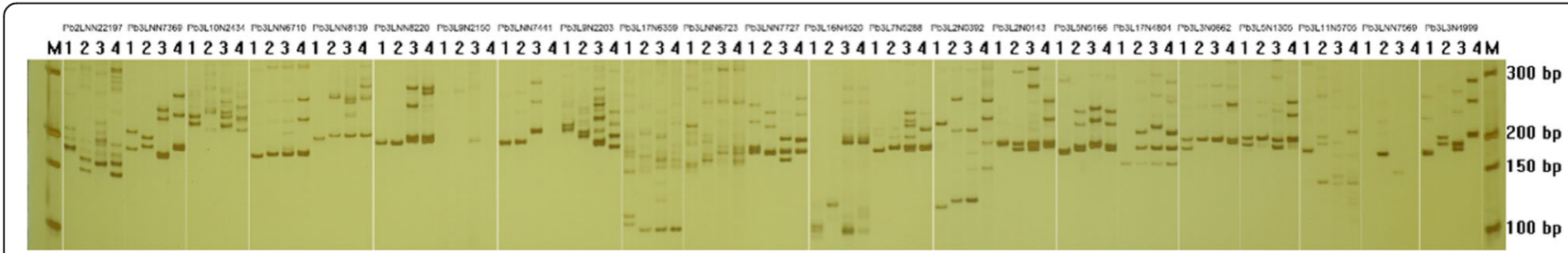

Fig. 3 PAGE results from the PCR amplification of 23 SSR primer pairs at a $60{ }^{\circ} \mathrm{C}$ annealing temperature. M: DL2000 DNA Ladder Marker (TaKaRa); 1: Red Clapp's Favorite; 2: Mansoo; 3: Mantianhong; 4: Hongxiangsu 
pear cultivars, including 9 European pear accessions and 5 hybrids derived from European pears, were grouped into one group, and 29 Asian pear varieties were clustered into one group (Fig. 4).

The Asian pear group can be further divided into 3 subgroups: the first subgroup is mainly composed of Chinese sand pear (P. pyrifolia) from Yunnan Province, China, and the offspring ('Mantianhong,' 'Meirensu', 'Hongsucui') of the Yunnan sand pear cultivar 'Huobali'. Cultivar 'Shuihongxiao' of white pear and cultivar 'Honghuaguan' of Pyrus ussuriensis from Hebei Province, China are also clustered in this group. The second subgroup is composed of 'Korla pear,' 'Pingguoli' and the descendants of 'Pingguoli', such as 'Hongxiangsu', 'Yuluxiang,' 'Xinli No.7' and 'Red Zaosu', which can be called the Chinese white pear ( $P$. bretschneideri) subgroup. The third subgroup is composed of "Wuxiangli' and other 6 varieties of Pyrus ussuriensis (Fig. 4).

In the population structure analysis, there is an obvious turning point for the estimated log probability of data when $\mathrm{K}=2$ (Fig. 5A-a). The first derivative (Fig. 5A-b), second derivative (Fig. 5A-c) and the peak value of the $\Delta \mathrm{K}$ score (Fig. $5 \mathrm{~A}-\mathrm{d}$ ) were found to be the greatest when $K=2$, suggesting that the 44 accessions were partitioned into two groups corresponding to the European pear group (Pop 1) and the Asian pear group (Pop 2) (Fig. 6a). The 15 accessions in Pop 1 and 29 accessions in Pop 2 were further analyzed using the same methods, and only Pop 2 was subdivided into two subpopulations (Fig. 5B). Subpopulation 1 included 15 accessions comprising all the 6 accessions from the second

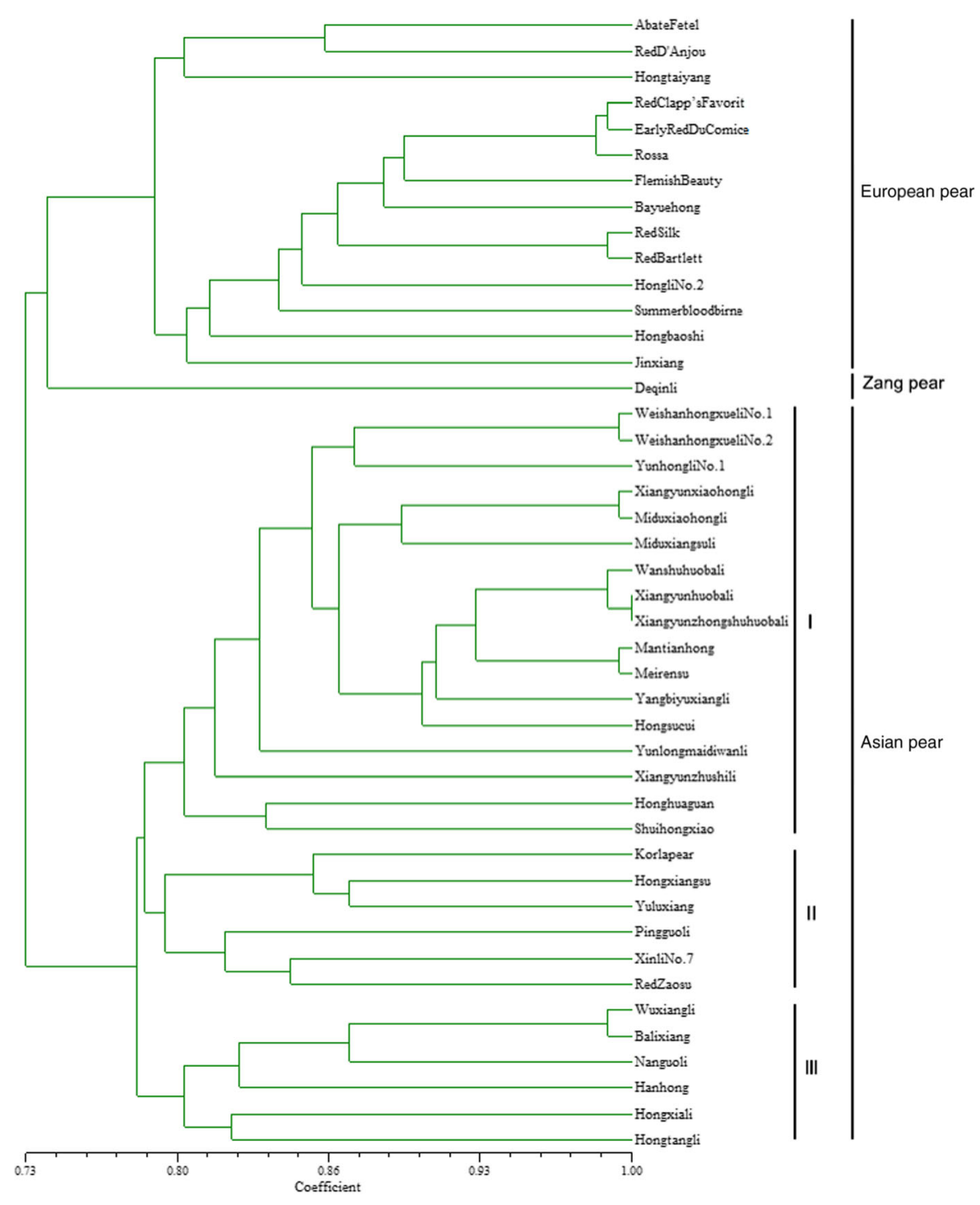

Fig. 4 Dendrogram for 44 pear cultivars derived from the UPGMA cluster analysis of 18 polymorphic SSR markers 


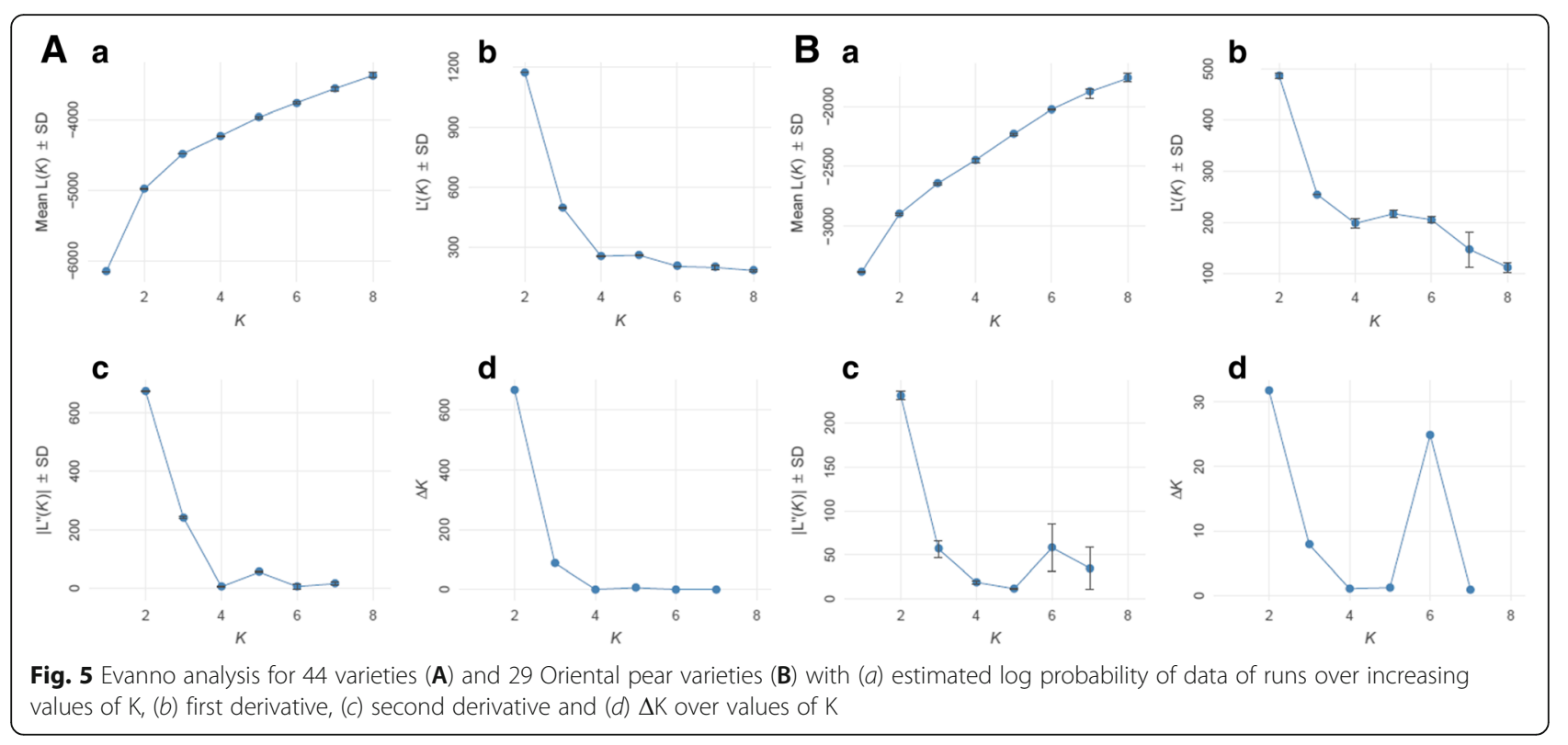

subgroup, all the 6 accessions from the third subgroup, and 3 accessions from the first group (Fig. 6b). In comparison, subpopulation 2 mainly comprised 14 out of 17 accessions from the first group obtained in the UPGMA cluster analysis (Fig. 6b). The results from the population structure analysis were generally consistent with the results from the UPGMA cluster analysis.

\section{Discussion}

SSRs can be divided into genomic SSRs and genic SSRs, and genomic SSRs are usually derived from SSRenriched genomic libraries or random genomic sequences, while genic SSRs are derived from coding regions of the transcriptome or EST sequences [17, 26, 29]. Compared with genomic SSR markers, genic SSR markers are considered to link to the loci of agronomic phenotypes and are more useful for marker assisted selection (MAS), especially when polymorphic genic SSR markers were identified in breeding lines $[29,30]$. Although genic SSRs are more effective, genome-wide mining of genomic SSRs is also a fundamental work. The availability of more and more whole-genome sequences for an increasing number of species will also greatly facilitate the development of genomic SSRs, and some research has also shown that SSRs in introns or other noncoding regions are also strongly associated with phenotypes [31, 32]. Pan et al. [32] found that genotypes of a TC microsatellite in an intron of PpYUC11 had strong association with the flesh texture (normal or stony hard) phenotypes of 43 peach varieties, and they considered that PpYUC11 might be responsible for the stony hard phenotype in peach. In other research, Kang et al. [31] reported that a chimeric mRNA (Psy1/Unknown), which was generated by joining exons from Psy1 and an unknown gene and resulted in the yellow-fruited phenotype of tomato accession PI 114490, might be caused by an SSR with $19 \mathrm{~A} / \mathrm{T}$ repeats in the downstream sequence of the Psy1 gene with Psy1/Unknown. A recent study shows that intron DNA sequences

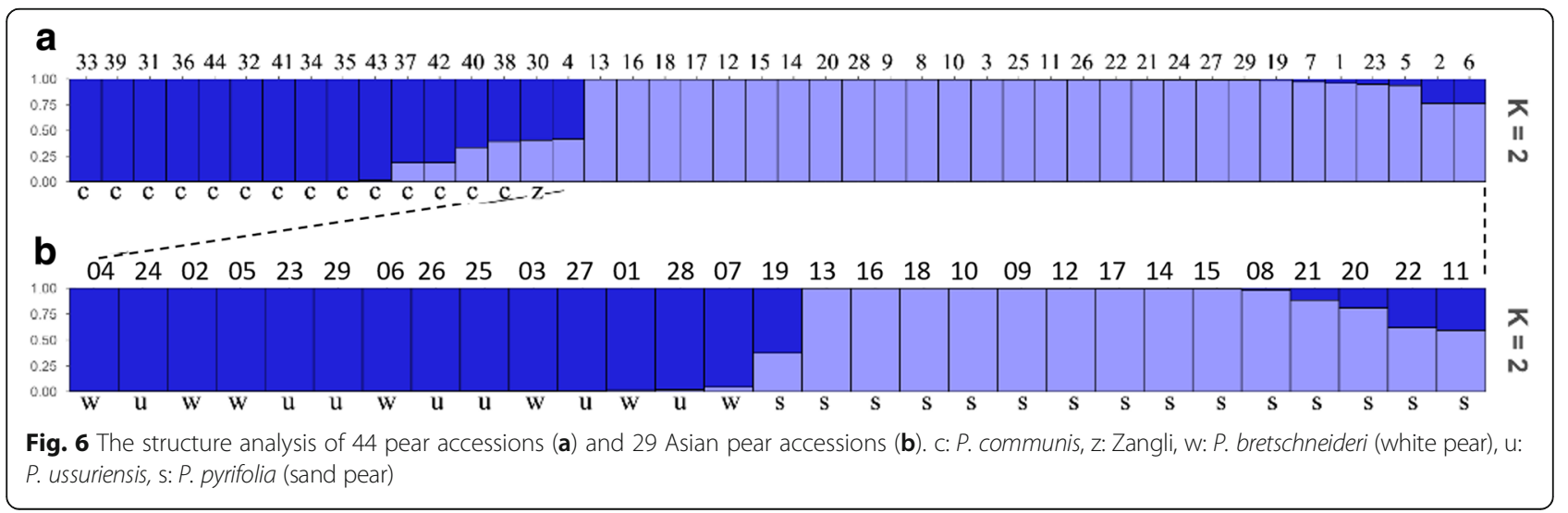


constitute a previously unrecognized type of downstream regulatory element for genes transcribed by RNA polymerase II and play an important role in determining the site of transcription initiation [33]. Clearly, the genomic SSRs located in introns and in the downstream sequence of genes may have the same enormous potential as genic SSRs in MAS applications. In the present study, a total of 49,384 SSR loci were identified from the intron and $1 \mathrm{~KB}$ upstream and downstream from the transcription initiation site, and a total of 7917 SSR loci were identified from the extrons, 5' UTR and 3' UTR, which demonstrates the importance of the development of SSR markers in the whole genome.

The functions of genic SSRs can often be inferred by performing a homology comparison of gene-containing genic SSRs, which is one of the reasons researchers think genic SSRs are more useful than genomic SSRs $[29,30]$. With the development of next-generation sequencing (NGS) technology, many species have had their whole genome sequenced, and the development of genomic SSR markers on a genome-wide scale using genomic sequencing data has gradually become an option of research [34-38]. The functions of the genomic SSRs developed from the related species can also be inferred from the gene annotation files or the function of neighboring genes. On the other hand, the genic SSRs developed from a specific transcriptome have a number of limitations due to the specificity of gene expression [26], while the genic SSRs developed from different material or tissue transcriptome data will compensate for this limitation to some extent, but it also increases the redundancy of genic SSRs, which has caused inconvenience to the application of genic SSR markers. Of course, genomic SSRs developed in early stages using genomic libraries or random DNA sequences also have the disadvantage of unclear location information and redundant loci, which are not conducive to applications.

In the present study, the 18 SSR loci distinguished the 44 pear individuals with an average of 10.56 alleles per locus and an average PIC value of 0.7808 , indicating a high level of polymorphism. Comparison of our results with previous findings of the SSR-based studies in Pear revealed that the average number of alleles per locus and PIC values recorded in the present study were compatible or higher than other SSR-based studies in Pyrus. Yue et al. [17] evaluated 28 Pyrus accessions with 28 genic SSR markers and identified 9.43 alleles per locus and an average PIC value of 0.585. Liu et al. [39] studied the group structure of 45 European pears (Pyrus communis L.) using 134 core SSR markers and showed that the average number of alleles per SSR locus was 5.45. Erfani et al. [40] studied the genetic diversity of 47 pear cultivars and genotypes using 28 SSR markers and showed that the average number of alleles per SSR locus was 6.21. Song et al. [15] in the study of genetic variability of 99 P. pyrifolia cultivars detected a mean of 4.93 alleles per locus for 134 SSR markers varying from 3 to 9 . Brini et al. [41] reported the average number of alleles per locus in pear ranged from 4 to 10, with an average of 7. Average PIC values obtained in our study were also somewhat higher when compared to the results of other authors. Wolko et al. [42] found PIC values were in the range of 0.42 to 0.89 with an average of 0.65 for the 19 high polymorphic SSR markers selected from 40 tested SSR markers. Dequigiovanni et al. [43] reported PIC values for 62 SSR loci among 42 pear accessions ranged from 0.48 to 0.87 , with an average of 0.67 . Yue et al. [17] reported an average PIC value of 0.58 for 28 SSRs in 28 Pyrus accessions (0.26 to 0.91). Erfani-Moghadam and Zarei [44] found PIC values of the SSR markers varied from 0.44 to 0.69 with an average of 0.59 . Thus, the randomly selected 18 SSR markers showed a high level of polymorphism. Some of the SSR markers developed in the present study have also been applied to construction of high-resolution linkage maps and QTL mapping analyses in pear by Wang et al. [45] and Wang et al. [46], respectively, which also proved advantageous to the application. The SSR markers developed in the present study are the most abundant pear SSR loci to date, and also provided the physical location and the estimated genetic positions for reference, which could significantly increase the efficiency of the related genomics studies, such as genetic diversity, constructing high-resolution linkage maps, QTL mapping, and so on.

In the present study, we used the UPGMA method to cluster the 44 pear varieties, and the European pears and Asian pears were clustered into different groups. A similar distinct clustering pattern has also been reported, and the Asian pear and European pear were completely separated from each other in the phylogenetic tree $[17,47]$ and probably evolved independently [48]. For the three subgroups of Asian pear, the phylogenetic tree showed that the relationship between subgroup I of sand pear and subgroup II of white pear is close. The subgroup of sand pear cultivars consisted of sand pear cultivars and the white pear cultivar 'Shuihongxiao', which have not been completely separated. This result is consistent with previous studies [13, 17, 47, 49] and proved that the correctness of the white pear cultivar group was assigned as a subgroup of sand pear of the $P$. pyrifolia white pear group [50]. In the previous studies, $P$. ussuriensis cultivars were considered to have originated from a hybrid between wild $P$. ussuriensis and $P$. bretschneideri [51], so P. ussuriensis cultivars were sometimes clustered alone [14] and sometimes clustered together with sand pear or white pear $[13,50]$. In the present study, we also obtained similar results, i.e., the $P$. ussuriensis cultivar 'Honghuaguan' was not clustered with the $P$. 
ussuriensis cultivars in subgroup III, but first with the white pear cultivar 'Shuihongxiao' and then clustered with the 15 sand pear cultivars as subgroup I of Asian pear.

Huobali is a group of local cultivars in Yunnan Province, China. 'Wanshuhuobali', 'Xiangyunhuobali' and 'Xiangyunzhongshuhuobali' are closely related cultivars to each other, all of which were clustered in subgroup I of Asian pear. 'Mantianhong, 'Hongsucui' and 'Meirensu', the descendants of their male parent Huobali (probably 'Anninghuobali'), were also clustered together with these three cultivars. Also in subgroup II, 'Hongxiangsu', 'Xinli No.7' and 'Yuluxiang', all of which were offspring of 'Korla pear', were clustered together with 'Korla pear'. Also grouped with these breeds are 'Xinli No.7' (filial generation of 'Korla pear' and 'Zaosu'), 'RedZaosu' (bud mutation of 'Zaosu') and 'Pingguoli' (female parent of 'Zaosu'). That these relatives were clustered together showed that the clustering results in this study were relatively reliable.

Zangli pear, a variety of landrace, distributed in the higher altitude junction region of Tibet, Yuannan and Sichuan Provinces in southwestern China, is a kind of semi-wild or semi-cultivated type, with hardy characteristics and resistance to a hypoxic environment. This type of pear is a potential germplasm resource available for resistance breeding in pear; for example, Zangli varieties 'Deqinli' pear, distributed in Deqin County of the Diqing Tibetan Autonomous Prefecture in Yunnan Province, China, have morphological characteristics of both Oriental and European pear, but its genetic relationship is closer to European pear, with smaller and leathery leaves. In the present study, the results of a cluster analysis of 44 pear cultivars with newly developed SSR markers also showed that the phylogenic status of 'Deqinli' in the dendrogram was rather special, indicating that it was closer to European pear. Another study also showed that the relationship between Zangli and sand pear cultivars from Sichuan, Yunnan and Guizhou Provinces was closer than that between Zangli and $P$. ussuriensis cultivars, but the European pears were not included in the study [52]. There are also some semi-cultivated pear cultivars with both Asian and European pear characteristics in Xinjiang Province, Northwest China. Among them, the variety 'Wanshu Duxiaxi' was clustered together with some European Pear cultivars, such as 'Batllet', 'La France' and 'Passe Crassane', into one group [47], indicating the genetic background of these semi-cultivated varieties have high similarities with European pear. To determine the relationships between these pear germplasm resources in Southwest China and Northwest China, and the relationship between them and other pear systems, further studies are still needed. This will help us better understand the origin and evolution of Pyrus, and at the same time, can help us make use of these resources.

\section{Conclusions}

In this study, we developed 101,694 genomic SSR markers from the reference genome sequences of pear. Among them, a total of 38,377 SSR marker loci were 26 base repeats, which is the largest number of SSR markers developed from a single development in pear by far. These SSR markers were also marked with the relative position information of both the physical location and the linkage groups, and the adjacent genes of the SSR loci were also annotated, which can provide better help for related research work and the developed SSR markers can be utilized by researchers and breeders for future pear improvement.

\section{Methods}

Plant materials and DNA extraction

A total of 44 accessions, planted in the Pear Germplasm Resources Garden in Zhengzhou, Zhengzhou Fruit Research Institute, Chinese Academy of Agricultural Sciences, were used in the present study (Tables 1 and 2). XGL is responsible for a formal and more detailed description of each of these pear accessions. The voucher specimens for these pear accessions used herein are deposited in Zhengzhou Fruit Research Institute, Chinese Academy of Agricultural Sciences, China. No specific permissions were required for these plant material, since these studies did not involve endangered or protected species. Young leaves of different accessions were collected in April 2016.

Genomic DNA was extracted using the modified CTAB (cetyltrimethy-lammonium bromide) method. The DNA quality and concentration were determined by electrophoresis in 1\% agarose gel and NanoDrop1000 spectrophotometry (NanoDrop, Thermo scientific, Wilmington, DE, USA). DNA were diluted with sterilized ultrapure water, normalized to $50 \mathrm{ng} / \mu \mathrm{L}$, and stored at $-20{ }^{\circ} \mathrm{C}$ until use.

\section{The identification and annotation of SSR motifs}

Scaffold sequences in a compressed file " 225117 ref_Pbr_v1.0_chrUn.fa" for the genome of 'Dangshansuli' pear were obtained through ftp://ftp.ncbi.nlm.nih.gov/ge nomes/Pyrus_x_bretschneideri/CHR_Un/ [27]. SSR motifs were identified using a Perl language script Msatfinder [53]. A minimum repeat threshold of twelve, eight, five, five, five, and five repeats were required for detecting mono-, di-, tri-, tetra-, penta- and hexa-nucleotide motifs, respectively. 
Table 1 The 44 accessions used in the polymorphism analysis

\begin{tabular}{|c|c|c|c|c|c|}
\hline No. & Accession & Identification No. & Parentage & Origin & Species \\
\hline 1 & Hongxiangsu & ZFRpyA9-13 & Korla pear× Eli & Henan, China & P. bretschneideri \\
\hline 2 & Pingguoli & ZFRpyA12-10 & Unknown & Jilin, China & P. bretschneideri \\
\hline 3 & Yuluxiang & ZFRpyA10-13 & Korla $\times$ Xuehua & Shanxi, China & P. bretschneideri \\
\hline 4 & Red Zaosu & ZFRpyA18-3 & Red mutation of Zaosu & Shan'xi, China & P. bretschneideri \\
\hline 5 & Korla pear & ZFRpyA10-6 & Unknown & Xinjiang, China & P. bretschneideri \\
\hline 6 & Xinli No.7 & ZFRpyA9-14 & Korla pear $\times$ Zaosu & Xinjiang, China & P. bretschneideri \\
\hline 7 & Shuihongxiao & ZFRpyA15-2 & Unknown & Hebei, China & P. bretschneideri \\
\hline 8 & Hongsucui & ZFRpyA1-4 & Kousui $\times$ Huobali & Henan, China & P. pyrifolia \\
\hline 9 & Mantianhong & ZFRpyA1-8 & Kousui $\times$ Huobali & Henan, China & P. pyrifolia \\
\hline 10 & Meirensu & ZFRpyA2-2 & Kousui $\times$ Huobali & Henan, China & P. pyrifolia \\
\hline 11 & Miduxiangsuli & ZFRpyB14-17 & Unknown & Yunnan, China & P. pyrifolia \\
\hline 12 & Miduxiaohongli & ZFRpyB14-20 & Unknown & Yunnan, China & P. pyrifolia \\
\hline 13 & Wanshuhuobali & ZFRpyB14-19 & Unknown & Yunnan, China & P. pyrifolia \\
\hline 14 & Weishanhongxueli No.1 & ZFRpyB14-32 & Unknown & Yunnan, China & P. pyrifolia \\
\hline 15 & Weishanhongxueli No.2 & ZFRpyB14-15 & Unknown & Yunnan, China & P. pyrifolia \\
\hline 16 & Xiangyunhuobali & ZFRpyB14-28 & Unknown & Yunnan, China & P. pyrifolia \\
\hline 17 & Xiangyunxiaohongli & ZFRpyB14-16 & Unknown & Yunnan, China & P. pyrifolia \\
\hline 18 & Xiangyunzhongshuhuobali & ZFRpyB14-38 & Unknown & Yunnan, China & P. pyrifolia \\
\hline 19 & Xiangyunzhushili & ZFRpyB14-18 & Unknown & Yunnan, China & P. pyrifolia \\
\hline 20 & Yangbiyuxiangli & ZFRpyB14-33 & Unknown & Yunnan, China & P. pyrifolia \\
\hline 21 & Yunhongli No.1 & ZFRpyA1-17 & Unknown & Yunnan, China & P. pyrifolia \\
\hline 22 & Yunlongmaidiwanli & ZFRpyB14-34 & Unknown & Yunnan, China & P. pyrifolia \\
\hline 23 & Hanhong & ZFRpyA14-1 & Nanguoli $\times$ Jinsu & Jilin, China & P. ussuriensis \\
\hline 24 & Nanguoli & ZFRpyA15-4 & Unknown & Liaoning, China & P. ussuriensis \\
\hline 25 & Balixiang & ZFRpyA17-10 & Unknown & Liaoning, China & P. ussuriensis \\
\hline 26 & Wuxiangli & ZFRpyA14-13 & Unknown & Liaoning, China & P. ussuriensis \\
\hline 27 & Hongtangli & ZFRpyB14-3 & Unknown & Hebei, China & P. ussuriensis \\
\hline 28 & Honghuaguan & ZFRpyB14-6 & Unknown & Hebei, China & P. ussuriensis \\
\hline 29 & Hongxiali & ZFRpyB14-14 & Unknown & Hebei, China & P. ussuriensis \\
\hline 30 & Deqinli & ZFRpyB16-12 & Unknown & Yunnan, China & Zangli \\
\hline 31 & Early Red Du Comice & ZFRpyA15-7 & Unknown & Britain & P. communis \\
\hline 32 & Red Bartlett & ZFRpyB17-22 & Bartlett mutation & America & P. communis \\
\hline 33 & Red Clapp's Favorite & ZFRpyA16-15 & Clapp's Favorite mutation & America & P. communis \\
\hline 34 & Red D'Anjou & ZFRpyA17-18 & Beurre D'Anjou mutation & America & P. communis \\
\hline 35 & Summer blood birne & ZFRpyA16-7 & Unknown & America & P. communis \\
\hline 36 & Flemish Beauty & ZFRpyA16-3 & Unknown & Belgium & P. communis \\
\hline 37 & Abate Fetel & ZFRpyA15-8 & Unknown & France & P. communis \\
\hline 38 & Hongbaoshi & ZFRpyD2-1 & Bayuehong $\times$ Dangshan suli & Henan, China & P. communis \\
\hline 39 & Rossa & ZFRpyA15-17 & Unknown & Italy & P. communis \\
\hline 40 & Jinxiang & ZFRpyB17-1 & Bartlett $\times$ Nanguoli & Liaoning, China & P. communis \\
\hline 41 & Bayuehong & ZFRpyB17-20 & Clapp's Favorite $\times$ Zaosu & Shan'xi, China & P. communis \\
\hline 42 & Hongli No.2 & ZFRpyA18-5 & Qiyuesu × Red Clapp's Favorite & Henan, China & P. communis \\
\hline 43 & Hongtaiyang & ZFRpyA17-14 & Clapp's Favorite $\times$ Xinglongmali & Henan, China & P. communis \\
\hline 44 & Red Silk & ZFRpyB17-16 & Unknown & America & P. communis \\
\hline
\end{tabular}


Table 2 Eighteen polymorphic SSR markers validated in the 44 pear accessions

\begin{tabular}{|c|c|c|c|c|c|}
\hline Marker & Repeat motif & Primer sequence $\left(5^{\prime} \rightarrow 3^{\prime}\right)$ & $\mathrm{Ta}\left({ }^{\circ} \mathrm{C}\right)$ & Expected length (bp) & Actual length (bp) \\
\hline Pb3L11N5758 & (aat)14 & $\begin{array}{l}\text { F: GGTGCTGTAAGGTGGTGATG } \\
\text { R: ATGAAACCAGCCAAACAACC }\end{array}$ & 58 & 224 & $183-225$ \\
\hline Pb3L4N5130 & (aat) 16 & $\begin{array}{l}\text { F: GCCTCCAGACTCAAACTTTCC } \\
\text { R: TGCGAGAGCGTAGGAGAAAT }\end{array}$ & 56 & 229 & $205-244$ \\
\hline Pb2LUN25693 & (ac) 23 & $\begin{array}{l}\text { F: CTTCGAAAGGTTCCCAGAAG } \\
\text { R: AAGTACGGACCAAGGTGCAG }\end{array}$ & 53 & 200 & $169-225$ \\
\hline Pb2L10N09474 & (ac) 23 & $\begin{array}{l}\text { F: CATAAGCACCCAAACTCGTG } \\
\text { R: GCCATGAGTCAAAGAGTCCAG }\end{array}$ & 58 & 244 & $208-250$ \\
\hline Pb3L15N3832 & (aca) 10 & $\begin{array}{l}\text { F: AATAGCGCATAGATCCAACCA } \\
\text { R: CCTCCCCATAAGCTTCATCA }\end{array}$ & 58 & 203 & 183-207 \\
\hline Pb3LUN6782 & (aca) 13 & $\begin{array}{l}\text { F: TGCTTTACAGCTGAGCTTCG } \\
\text { R: AAGTITCCCTCGGGGTITIA }\end{array}$ & 58 & 213 & $184-211$ \\
\hline Pb2L15N13836 & $(\mathrm{ag}) 20$ & $\begin{array}{l}\text { F: CGTCTTGAACCACCATCTCC } \\
\text { R: CCACTITCTTCCACCACCAT }\end{array}$ & 56 & 199 & $173-211$ \\
\hline Pb2L2N00815 & $(\mathrm{ag}) 20$ & $\begin{array}{l}\text { F: CCAAACACATGACCACAAGC } \\
\text { R: AAATGGAGCAGGTGGGAGTA }\end{array}$ & 56 & 192 & 164-198 \\
\hline Pb2L10N09198 & $(\mathrm{ag}) 20$ & $\begin{array}{l}\text { F: GAGAAATGCAGTGGGGATTG } \\
\text { R: AAAGTGACCGCTCAAAATGC }\end{array}$ & 56 & 205 & 179-207 \\
\hline Pb2LUN24134 & $(\mathrm{ag}) 21$ & $\begin{array}{l}\text { F: AAGCTGGTTATGTGGCTGCT } \\
\text { R: ATTGAGTTCGCTCGTTCGTT }\end{array}$ & 56 & 204 & $171-197$ \\
\hline Pb2L17N16884 & $(\mathrm{ag}) 21$ & $\begin{array}{l}\text { F: TTGTGCCCTIITICCTACCA } \\
\text { R: GGGCTAAACGCTTTGATGTT }\end{array}$ & 58 & 197 & $107-147$ \\
\hline Pb2L8N07068 & $(\mathrm{ag}) 21$ & $\begin{array}{l}\text { F: AGGAGCTAGCATGCTTGGGA } \\
\text { R: CGACACGAACACAAGAAACA }\end{array}$ & 56 & 192 & $103-275$ \\
\hline Pb2L1N00036 & $(\mathrm{ag}) 22$ & $\begin{array}{l}\text { F: CACTATGCCAGTGACAAAGATTG } \\
\text { R: AGTAGATGCTAGGGCCACCA }\end{array}$ & 58 & 198 & $174-214$ \\
\hline Pb2L7N06609 & $(\mathrm{ag}) 22$ & $\begin{array}{l}\text { F: ACCCTAGTCGTCGTTCTTGC } \\
\text { R: GCAGAGACGGAAAGAAATGG }\end{array}$ & 56 & 207 & 149-207 \\
\hline Pb2L4N03431 & $(\mathrm{ag}) 22$ & $\begin{array}{l}\text { F: CCCAAAAGTAACCGAGCGTA } \\
\text { R: TTCAGCCAGCCACTCTCTCT }\end{array}$ & 56 & 191 & $168-200$ \\
\hline Pb3L2N0143 & (aga) 12 & $\begin{array}{l}\text { F: ACCAGAACCCACTCACCATC } \\
\text { R: CCGACAATAAAGGCCTCAA C }\end{array}$ & 56 & 198 & 178-199 \\
\hline Pb3L5N5166 & (aga) 12 & $\begin{array}{l}\text { F: CGAGAGCGCCTAAGAGAAGA } \\
\text { R: CGGAGACTCGCTGACTCACT }\end{array}$ & 58 & 211 & 182-209 \\
\hline Pb4L1N0014 & (cata)11 & $\begin{array}{l}\text { F: TCCCTTCAAGGCTGTGAGTT } \\
\text { R: CAGAGGTTGGTTTTGGTGA }\end{array}$ & 58 & 211 & $172-208$ \\
\hline
\end{tabular}

We carried out the SSR annotation from the reference genome with the Generic Feature Format 3 (GFF3) (ftp://ftp.ncbi.nlm.nih.gov/genomes/Pyrus_x_bretschneideri/GFF/) using the ANNOVAR software [54]. To annotate the genes, we used the BLASTx (version 2.3.5) program (https://blast.ncbi.nlm.nih.gov/Blast.cgi) with an E-value threshold of $1 \mathrm{e}-5$ to the NCBI non-redundant protein $(\mathrm{Nr})$ database (http:// www.ncbi.nlm.nih.gov) and the Kyoto Encyclopedia of Genes and Genomes (KEGG) database (http://www.genome.jp/kegg). Protein functional annotations could then be obtained according to the best alignment results. The $\mathrm{GO}$ annotation of genes was analyzed by the Blast2GO software (version 2.6.0+) [55], and the functional classification of genes was completed using WEGO software [56].

\section{Primer design and marker validation}

Based on SSR motifs, the Primer 3 software [57] was used to design SSR primers with the following parameters: the length of primers was in the range of 18 $28 \mathrm{bp}$, with $20 \mathrm{bp}$ as the optimum; the product size range was from 100 to $300 \mathrm{bp}$; and the melting temperature $(\mathrm{Tm})$ was in the range of $55-65{ }^{\circ} \mathrm{C}$, with $60{ }^{\circ} \mathrm{C}$ as the optimum and a maximum Tm difference of $1{ }^{\circ} \mathrm{C}$. Primers of the SSRs with compound motif types were discarded. All the primer sequences were compared with each other, and the primers with more than one copy were deleted to verify that each primer pair amplified only a single SSR. These newly developed scaffold-derived SSR markers were then aligned to the high-density genetic linkage map [28] according to the scaffolds' genetic positions, which were defined 
as the average genetic position of the SNPs on a scaffold of the map. Each primer pair was named with the prefix code $\mathrm{Pb}$ (Pyrus bretschneideri), followed by the repeated motif type, a linkage group number and a consecutive number.

A total of 534 primers were randomly selected from the newly designed primers to first validate for polymerase chain reaction (PCR) and SSR polymorphisms among four pear accessions (Red Clapp's Favorite, Hongsucui, Mantianhong and Hongxiangsu). The PCR reaction was carried out in a reaction mixture with a volume of $20 \mu \mathrm{L}$ comprised of $1.0 \mu \mathrm{L}(50 \mathrm{ng})$ of template DNA, $2.0 \mu \mathrm{L}$ of $10 \times$ PCR buffer $\left(\mathrm{Mg}^{2+}\right.$ plus), $0.1 \mu \mathrm{L}$ of Taq DNA polymerase solution ( 5 unit/ $\mu \mathrm{L}$ ), $1.6 \mu \mathrm{L}$ of $25 \mathrm{mM}$ dNTPs, $0.6 \mu \mathrm{L}$ $(10 \mu \mathrm{M})$ of each primer solution and $14.1 \mu \mathrm{L}$ of sterilized $\mathrm{ddH}_{2} \mathrm{O}$. The PCR reagents (buffer, $\mathrm{MgCl}_{2}$, dNTPs and Taq) were purchased from TaKaRa Bio Engineering Co., Ltd. (Dalian, China), and the primers were synthesized by GENEWIZ Bioengineering Ltd. (Beijing, China). Amplification was programmed as $5 \mathrm{~min}$ at $94{ }^{\circ} \mathrm{C}$ for initial denaturation; 30 cycles consisting of $30 \mathrm{~s}$ at $94{ }^{\circ} \mathrm{C}$ for denaturation, $30 \mathrm{~s}$ at the annealing temperature (Ta) for annealing, $45 \mathrm{~s}$ at $72{ }^{\circ} \mathrm{C}$ for extension; and finally, a 10 -min extension step at $72{ }^{\circ} \mathrm{C}$. The PCR products were loaded for electrophoresis in an $8 \%$ polyacrylamide gel.

Based on the screening results, 18 polymorphic primer pairs were further used to genotype the 44 pear accessions using the same volume and PCR program. Forward primers of the 18 primer pairs were $5^{\prime}$ end labeled with a fluorescent dye (HEX or FAM). The PCR products were identified on an ABI 3130 genetic analyzer (Applied Biosystems, Foster City, CA, USA). Determination of the fragment sizes and data collection were done using the GeneMapper 4.0 software (Applied Biosystems, Foster City, CA, USA).

\section{Data analysis}

The genotyping data of the accessions in the 18 SSR loci selected in the initial screening were then used to evaluate the genetic diversity of the 44 pear accessions. To estimate the genetic diversity among the pear accessions, some parameters were calculated using the software POPGENE version 1.32 [58], including the number of alleles $(\mathrm{Na})$, number of genotypes $(\mathrm{Ng})$, major allele frequency (A), observed heterozygosity (Ho), and expected heterozygosity $(\mathrm{He})$. The polymorphism information content (PIC) of each locus was calculated using the software PowerMarker version 3.25 [59]. The software program NTSYS-pc2.10 was used to conduct a cluster analysis using the UPGMA method [60]. Population structure was analyzed and visualized using $R$ package POPHELPER [61] and STRUCTURE 2.3.4 [62].

\section{Additional files}

Additional file 1: Figure S1. Percentages of different motifs among mono-(a), di- (b) and tri- (c) nucleotide repeats in the 'Dangshansuli' pear genome. (PDF 183 kb)

Additional file 2: Table S1. Frequency of different SSR repeat motifs. (XLSX $9 \mathrm{~kb}$ )

Additional file 3: Table S2. Frequency distribution of different SSR motifs. (XLSX 9 kb)

Additional file 4: Table S3. Type and number of repeat motifs. (XLSX $10 \mathrm{~kb}$ ) Additional file 5: Table S4. Statistics of SSRs in different categories. (XLSX $9 \mathrm{~kb}$ )

Additional file 6: Table S5. Number of different types of SSR motifs in different LGs. (XLSX $10 \mathrm{~kb}$ )

Additional file 7: Table S6. Information of new designed 101, 694 SSR primers, including information of the primer sequences, annealing temperature $(\mathrm{Ta})$, repeat motifs, target size, linkage groups, and positions in genetic and physical maps of pear. (XLSX $10192 \mathrm{~kb}$ )

Additional file 8: Table S7. Information of 534 SSR primers, including information of the primer sequences, annealing temperature ( $\mathrm{Tm})$, repeat motifs, target size, linkage groups, and positions in genetic and physical maps of pear. (XLSX $72 \mathrm{~kb}$ )

Additional file 9: Table S8. Information of 332 good SSR primers, including information of the primer sequences, annealing temperature $(\mathrm{Tm})$, repeat motifs, target size. (XLSX $36 \mathrm{~kb}$ )

Additional file 10: Figure S2. Amplified fragments of Pb3L11N5758 and Pb3L4N5130 SSR loci from five pear varieties. (PDF $188 \mathrm{~kb}$ )

Additional file 11: Table S9. Polymorphism information of 18 primers in 44 pear cultivars. (XLSX $10 \mathrm{~kb}$ )

Additional file 12: Table S10. Similarity coefficient among 44 pear cultivars. (XLSX $18 \mathrm{~kb}$ )

\section{Acknowledgements}

We thank Dr. Richard Volz (Hawke's Bay Research Centre, The New Zealand Institute for Plant and Food Research Limited) for comments on this manuscript.

\section{Funding}

This work was supported by the Science-Technology Project of Henan province (172102110244), Central Public-Interest Scientific Institution Basal Research Fund (1610192017709), the National Natural Science Foundation of China (31272140), and the Agricultural Science and Technology Innovation Program (ASTIP) (CAAS-ASTIP).

\section{Availability of data and materials}

All data generated or analysed during this study are included in this published article [and its Additional files].

\section{Authors' contributions}

HBX, YSQ and XGL conceived and designed the research; HBX, PJZ, TS, JY, LW, SKW, YLS and HRZ performed the research and analyzed the data; HBX and PJZ interpreted the results and wrote the manuscript. All authors read and approved the final manuscript.

\section{Ethics approval}

The Pear plant samples were obtained from the Pear Germplasm Resources Garden in Zhengzhou, Zhengzhou Fruit Research Institute, Chinese Academy of Agricultural Sciences, China. Since these studies did not involve endangered or protected species, no specific permissions are required for these material.

The authors declared that experimental research works on the plants described in this paper comply with institutional and national guidelines.

Competing interests

The authors declare that they have no competing interests. 


\section{Publisher's Note}

Springer Nature remains neutral with regard to jurisdictional claims in published maps and institutional affiliations.

Received: 13 February 2018 Accepted: 23 May 2018

Published online: 18 June 2018

\section{References}

1. Potter D, Eriksson T, Evans RC, Oh S, Smedmark J, Morgan DR, Kerr M, Robertson KR, Arsenault M, Dickinson TA. Phylogeny and classification of Rosaceae. Plant Syst Evol. 2007:5-43.

2. Vavilov NI. The origin, variation, immunity and breeding of cultivated plants, vol. 72: LWW; 1951.

3. Collard B, Jahufer M, Brouwer J, Pang E. An introduction to markers, quantitative trait loci (QTL) mapping and marker-assisted selection for crop improvement: the basic concepts. Euphytica. 2005;142(1-2):169-96.

4. Collard BC, Mackill DJ. Marker-assisted selection: an approach for precision plant breeding in the twenty-first century. Philos Trans R Soc Lond B Biol Sci. 2008;363(1491):557-72.

5. Lv H, Wang Q, Han F, Liu X, Fang Z, Yang L, Zhuang M, Liu Y, Li Z, Zhang Y. Genome-wide indel/SSR scanning reveals significant loci associated with excellent agronomic traits of a cabbage (Brassica oleracea) elite parental line '01-20'. Sci Rep. 2017;7:41696.

6. Gur-Arie R, Cohen CJ, Eitan Y, Shelef L, Hallerman EM, Kashi Y. Simple sequence repeats in Escherichia coli: abundance, distribution, composition, and polymorphism. Genome Res. 2000;10(1):62-71.

7. Tautz D, Renz M. Simple sequences are ubiquitous repetitive components of eukaryotic genomes. Nucleic Acids Res. 1984;12(10):4127-38.

8. Tóth G, Gáspári Z, Jurka J. Microsatellites in different eukaryotic genomes: survey and analysis. Genome Res. 2000;10(7):967-81.

9. Ellegren H, Moore S, Robinson N, Byrne K, Ward W, Sheldon BC. Microsatellite evolution-a reciprocal study of repeat lengths at homologous loci in cattle and sheep. Mol Biol Evol. 1997;14(8):854-60.

10. Powell W, Machray GC, Provan J. Polymorphism revealed by simple sequence repeats. Trends Plant Sci. 1996;1(7):215-22.

11. Chen H, Song Y, Li L-T, Khan MA, Li X-G, Korban SS, Wu J, Zhang S-L. Construction of a high-density simple sequence repeat consensus genetic map for pear (Pyrus spp.). Plant Mol Biol Rep. 2015;33(2):316-25.

12. Sawamura Y, Saito T, Takada N, Yamamoto T, Kimura T, Hayashi T, Kotobuki K. Identification of parentage of Japanese pear 'Housui'. J Jap Soc Horticult Sci. 2004;73(6):511-8.

13. Kimura T, Shi $Y Z$, Shoda M, Kotobuki K, Matsuta N, Hayashi T, Ban Y, Yamamoto T. Identification of Asian pear varieties by SSR analysis. Breed Sci. 2002;52(2):115-21.

14. Bao L, Chen K, Zhang D, Cao Y, Yamamoto T, Teng Y. Genetic diversity and similarity of pear (Pyrus L.) cultivars native to East Asia revealed by SSR (simple sequence repeat) markers. Genet Resour Crop Evol. 2007;54(5):959-71.

15. Song $Y$, Fan $L$, Chen $H$, Zhang $M, M a ~ Q$, Zhang $S$, Wu J. Identifying genetic diversity and a preliminary core collection of Pyrus pyrifolia cultivars by a genome-wide set of SSR markers. Sci Hortic. 2014;167:5-16.

16. Thammina CS, Olsen RT, Kramer M, Pooler MR. Genetic relationships of boxwood (Buxus L.) accessions based on genic simple sequence repeat markers. Genet Resour Crop Evol. 2017;64(6):1281-93.

17. $X-Y$ Y, G-Q L, Zong Y, Teng Y-W, Cai D-Y. Development of genic SSR markers from transcriptome sequencing of pear buds. J Zhejiang Univ Sci B. 2014;15(4):303.

18. Fan L, Zhang M-Y, Liu Q-Z, Li L-T, Song Y, Wang L-F, Zhang S-L, Wu J. Transferability of newly developed pear SSR markers to other Rosaceae species. Plant Mol Biol Rep. 2013;31(6):1271-82.

19. Fernández-Fernández F, Harvey N, James C. Isolation and characterization of polymorphic microsatellite markers from European pear (Pyrus communis L.). Mol Ecol Resour. 2006;6(4):1039-41.

20. Nishitani C, Terakami S, Sawamura Y, Takada N, Yamamoto T. Development of novel EST-SSR markers derived from Japanese pear (Pyrus pyrifolia). Breed Sci. 2009;59(4):391-400

21. Yamamoto T, Kimura T, Sawamura Y, Manabe T, Kotobuki K, Hayashi T, Ban Y, Matsuta N. Simple sequence repeats for genetic analysis in pear. Euphytica. 2002:124(1):129-37.

22. Yamamoto T, Kimura T, Shoda M, Ban Y, Hayashi T, Matsuta N. Development of microsatellite markers in the Japanese pear (Pyrus pyrifolia Nakai). Mo Ecol Resour. 2002;2(1):14-6.
23. Yamamoto T, Kimura T, Shoda M, Imai T, Saito T, Sawamura Y, Kotobuki K, Hayashi T, Matsuta N. Genetic linkage maps constructed by using an interspecific cross between Japanese and European pears. Theor Appl Genet. 2002:106(1):9-18.

24. Yamamoto T, Terakami S, Moriya S, Hosaka F, Kurita K, Kanamori H, Katayose $Y$, Saito T, Nishitani C. DNA markers developed from genome sequencing analysis in Japanese pear (Pyrus pyrifolia). XIII Eucarpia Symposium on Fruit Breeding and Genetics. 2011;976(2011):477-83.

25. Zhang M, Fan L, Liu Q, Song Y, Wei S, Zhang S, Wu J. A novel set of ESTderived SSR markers for pear and cross-species transferability in Rosaceae. Plant Mol Biol Rep. 2014;32(1):290-302.

26. Zhou H, Cai B, Lü Z, Gao Z, Qiao Y. Development, characterization, and annotation of potential simple sequence repeats by transcriptome sequencing in pears (Pyrus pyrifolia Nakai). Genet Mol Res. 2016;15(3)

27. Wu J, Wang Z, Shi Z, Zhang S, Ming R, Zhu S, Khan MA, Tao S, Korban SS, Wang $\mathrm{H}$. The genome of the pear (Pyrus bretschneideri Rehd.). Genome Res. 2013:23(2):396-408

28. Wu J, Li LT, Li M, Khan MA, Li XG, Chen H, Yin H, Zhang SL. High-density genetic linkage map construction and identification of fruit-related QTLs in pear using SNP and SSR markers. J Exp Bot. 2014;65(20):5771-81.

29. Varshney RK, Graner A, Sorrells ME. Genic microsatellite markers in plants: features and applications. Trends Biotechnol. 2005;23(1):48-55.

30. Dutta S, Kumawat G, Singh BP, Gupta DK, Singh S, Dogra V, Gaikwad K, Sharma TR, Raje RS, Bandhopadhya TK. Development of genic-SSR markers by deep transcriptome sequencing in pigeonpea [Cajanus cajan (L.) Millspaugh]. BMC Plant Biol. 2011;11(1):17.

31. Kang B, Gu Q, Tian P, Xiao L, Cao H, Yang W. A chimeric transcript containing Psy 1 and a potential mRNA is associated with yellow flesh color in tomato accession PI 114490. Planta. 2014;240(5):1011-21.

32. Pan L, Zeng W, Niu L, Lu Z, Liu H, Cui G, Zhu Y, Chu J, Li W, Fang W. PpYUC11, a strong candidate gene for the stony hard phenotype in peach (Prunus persica L. Batsch), participates in IAA biosynthesis during fruit ripening. J Exp Bot. 2015;66(22):7031-44.

33. Gallegos JE, Rose AB. Intron DNA sequences can be more important than the proximal promoter in determining the site of transcript initiation. Plant Cell. 2017;29(4):843-53.

34. Li Q, Zhang J, Yao J, Wang X, Duan D. Development of Saccharina japonica genomic SSR markers using next-generation sequencing. J Appl Phycol. 2016;28(2):1387-90.

35. Liu Z, Tao J, Luo Y. Development and characterization of polymorphic genomic-SSR markers in Asian long-horned beetle (Anoplophora glabripennis). B Entomol Res. 2017:1-7.

36. Portis E, Portis F, Valente L, Moglia A, Barchi L, Lanteri S, Acquadro A. A genome-wide survey of the microsatellite content of the globe artichoke genome and the development of a web-based database. PLoS One. 2016; 11(9):e0162841.

37. Zhang L, Peng J, Li X, Cui C, Sun J, Yang G. Characterization of genome-wide microsatellites of Saccharina japonica based on a preliminary assembly of Illumina sequencing reads. J Ocean Univ China. 2016:15(3):523-32.

38. Zhu H, Guo L, Song P, Luan F, Hu J, Sun X, Yang L. Development of genome-wide SSR markers in melon with their cross-species transferability analysis and utilization in genetic diversity study. Mol Breeding. 2016;36(11):153.

39. Liu Q, Song Y, Li J, Zhang M, Qi K, Zhang S, Wu J. Analysis of genetic diversity of European pear (Pyrus communis L.) cultivars using core simple sequence repeat (SSR) markers. Journal of Agricultural Biotechnology. 2015;23(5):579-87.

40. Erfani J, Ebadi A, Abdollahi H, Fatahi R. Genetic diversity of some pear cultivars and genotypes using simple sequence repeat (SSR) markers. Plant Mol Biol Rep. 2012;30(5):1065-72.

41. Brini W, Mars M, Hormaza J. Genetic diversity in local Tunisian pears (Pyrus communis L) studied with SSR markers. Sci Hortic Amsterdam. 2008:115(4):337-41.

42. Wolko $Ł$, Antkowiak W, Lenartowicz E, Bocianowski J. Genetic diversity of European pear cultivars (Pyrus communis L.) and wild pear (Pyrus pyraster (L.) Burgsd.) inferred from microsatellite markers analysis. Genet Resour Crop Evol. 2010:57(6):801-6.

43. Dequigiovanni G, Rech F, Gomes FGG, Cerotti IS, Faoro I. Oliveira PRDd, Quecini $V$, Ritschel P. Identification of a simple sequence repeat molecularmarker set for large-scale analyses of pear germplasm. Crop Breed Appl Biotechnol. 2012;12(2):118-25.

44. Erfani-Moghadam J, Zarei A. Assessment of genetic structure among different pear species (Pyrus spp.) using apple-derived SSR and evidence of duplications in the pear genome. Biotechnol Biotec Eq. 2018:1-11. 
45. Wang L, Li X, Wang L, Xue H, Wu J, Yin H, Zhang S. Construction of a highdensity genetic linkage map in pear (Pyrus communis $\times$ Pyrus pyrifolia nakai) using SSRs and SNPs developed by SLAF-seq. Sci Hortic. 2017;218:198-204.

46. Wang $L, L i X G$, Xue HB, Li J. Mapping QTLs for fruit related traits in pear. 2016;43

47. Teng Y, Tanabe $K$, Tamura F, Itai A. Genetic relationships of pear cultivars in Xinjiang, China, as measured by RAPD markers. J Hortic Sci Biotechnol. 2001; 76(6):771-9.

48. Iketani H, Manabe T, Matsuta N, Akihama T, Hayashi T. Incongruence between RFLPs of chloroplast DNA and morphological classification in east Asian pear (Pyrus spp.). Genet Resour Crop Evol. 1998;45(6):533-9.

49. Liu Q, Song Y, Liu L, Zhang M, Sun J, Zhang S, Wu J. Genetic diversity and population structure of pear (Pyrus spp.) collections revealed by a set of core genome-wide SSR markers. Tree Genet Genom. 2015;11(6):128.

50. Bao $L$, Chen $K$, Zhang D, Li X, Teng Y. An assessment of genetic variability and relationships within Asian pears based on AFLP (amplified fragment length polymorphism) markers. Sci Hortic-Amsterdam. 2008:1 16(4):374-80.

51. Yu P, Jiang S, Wang X, Bai S, Teng Y. Retrotransposon-based sequencespecific amplification polymorphism markers reveal that cultivated Pyrus ussuriensis originated from an interspecific hybridization. Eur J Hortic Sci. 2016;81(5):264-72.

52. Xue L, Liu Q, Qin M, Zhang M, Wu X, Wu J. Genetic variation and population structure of "Zangli" pear landraces in Tibet revealed by SSR markers. Tree Genet Genomes. 2017;13(1):26.

53. Thurston M, Field D. Msatfinder: detection and characterisation of microsatellites. Oxford: CEH Oxford In; 2005

54. Wang K, Li M, Hakonarson H. ANNOVAR. Functional annotation of genetic variants from high-throughput sequencing data. Nucleic Acids Res. 2010; 38(16):e164-e164

55. Conesa A, Götz S, García-Gómez JM, Terol J, Talón M, Robles M. Blast2GO: a universal tool for annotation, visualization and analysis in functional genomics research. Bioinformatics. 2005;21(18):3674-6

56. Ye J, Fang L, Zheng H, Zhang Y, Chen J, Zhang Z, Wang J, Li S, Li R, Bolund L. WEGO: a web tool for plotting GO annotations. Nucleic Acids Res. 2006; 34(suppl_2):W293-7.

57. Koressaar T, Remm M. Enhancements and modifications of primer design program Primer3. Bioinformatics. 2007:23(10):1289-91.

58. Yeh F. Population genetic analysis of codominant and dominant markers and quantitative traits. Belg J Bot. 1997:129:157.

59. Liu K, Muse SV. PowerMarker: an integrated analysis environment for genetic marker analysis. Bioinformatics. 2005;21(9):2128-9.

60. Rohlf F. NTSYS-pc version 2.2. Numerical Taxonomy and Multivariate. Analysis System Exter Publ New York. 1997.

61. Francis RM. POPHELPER: an R package and web app to analyse and visualize population structure. Mol Ecol Resour. 2017;17(1):27-32.

62. Pritchard K, Stephens M, Donnelly P. Inference of population structure using multilocus genotype data [J]. Genetics, 2000;155(2):945-59.

\section{Ready to submit your research? Choose BMC and benefit from:}

- fast, convenient online submission

- thorough peer review by experienced researchers in your field

- rapid publication on acceptance

- support for research data, including large and complex data types

- gold Open Access which fosters wider collaboration and increased citations

- maximum visibility for your research: over $100 \mathrm{M}$ website views per year

At BMC, research is always in progress.

Learn more biomedcentral.com/submissions 